\title{
Open transformation
}

\author{
January is traditionally a time for looking back over years past and making plans for the year to come. For \\ Nature Plants, this means a first transformative step towards open access.
}

$\mathrm{t}$ is difficult to believe that Nature Plants has been in existence for six years. It feels like a very short time since we were celebrating the publication of our first issue. The previous year (2014) had been turbulent with troubles in Ukraine, including the annexation of Crimea by Russia. The Islamic State of Iraq and the Levant had started a military offensive to capture Baghdad. Malaysia Airlines Flight 370, carrying 239 people from Kuala Lumpur to Beijing, disappeared over the Gulf of Thailand. And the shooting of Michael Brown by a police officer triggered riots in Ferguson, Missouri, and in other cities in the United States.

There was also a major ongoing coronavirus outbreak (MERS-CoV) concentrated in the countries of the Middle East. While such events seem worryingly familiar there were others that seem more fantastic; there had been a Winter Olympic Games in Sochi, Russia and a football World Cup in Brazil (and won by Germany), both watched by thousands of spectators - in person!

Since the journal's launch we have also changed while remaining much the same. In our first issue we published a paper concerning the domestication of maize in the Southwestern United States ${ }^{1}$, and in this issue we have research looking at the different genomic trajectories taken by maize and sorghum since their domestication $^{2}$. In 2015 we published work on the molecular biochemistry of photosynthesis concerning the control of Rubisco activity ${ }^{3}$, and this month we have research looking at the dynamics of thylakoid stacking ${ }^{4}$.

Our first issue also demonstrated our interest in the politics of genome editing and global agriculture with two Comment articles ${ }^{5,6}$, topics that we are still pursuing. In our December issue we published a Correspondence discussing the consequences of the French Government's recent decree on permissible genetic modification techniques which, if implemented, would see crops that have been in use for many years being banned from cultivation in France ${ }^{7}$. Also, in October we published a number of articles that formed part of the 'Sustainable solutions to end hunger' Collection.
Despite this consistency we have also changed in both small and large ways. The journal has grown from 76 published research articles in 2015, to 124 in 2020. However, we have not expanded the scope of the research that we consider - rather, the currents of scientific research constantly take us into previously unexplored or unconsidered waters. The concept of the pan-genome was not much discussed six years ago and the dynamics of masting was an omission from the list of 'hot topics to cover' in our pre-launch plans. Both have featured multiple times in 2020.

A substantial development for 2021 is that we are now able to offer authors the option of publishing their research under an Open Access (OA) licence. This sounds like a simple change as so many other journals have this facility, but our ultimate aim is for Nature Plants (and the Nature Research journals, including Nature itself) to transition over the coming years to the point where all the research we publish will be $\mathrm{OA}$, while maintaining the care, quality and selectivity to which we aspire. This is far from easy to achieve and will require changes not only by the journal, its authors and readers, but also in the attitudes of universities and funding bodies to their role in the publication of research. There will be experiments with new and different ways to support our activities, which will be a substantial change for Nature Plants as we have until now not charged any author for any aspect of publication.

Despite these changes, it is very important to note that our peer-review and decision-making processes will not be influenced by whether authors opt for OA publication or not. This information will not be disclosed to the editors and we have no targets or quotas for how much OA content Nature Plants will publish this year, or any other. We also do not have a date in mind for when all our research content will be OA. We know that this is our destination but we can only guess how long the journey might be. It will take as long as it takes.

Nature Plants has already published OA content; 19 research papers have been OA at the time of writing. These papers report the sequencing of novel genomes and it has been a convention in the genome community dating back to the publication of the Human Genome Project, and a little beyond - that such initial genome sequencing is published OA. Those papers incurred no publication charges, but from now on genome sequencing studies will need to follow our standard route towards OA publication, and will be associated with an article processing charge when accepted.

It is fundamental to us that no researcher who wants to publish their work in Nature Plants should be prevented from doing so for reasons of cost. For the foreseeable future, our current 'standard' route to publication will remain, and will continue to involve no charges to authors. Ultimately, however, we intend for all of the research we publish to be OA and for authors to have no need to worry over the costs of publication. We are therefore enthusiastic about the agreement that has been made between Springer Nature and the Max Planck Digital Library, whereby researchers at Max Planck institutes will have both full access to all content published in Nature titles (including the Nature Reviews journals) and seamless OA publishing of their research articles accepted for publication in Nature journals. We hope that this will be a model for many other transformative agreements in the future.

As befits this time of year, we are looking back at the achievements and shortfalls that we have endured so that we can look forward to greater things built on their lessons. The inclusion of a route to OA publication will be a truly transformative step for Nature Plants, while maintaining all the positives of the journal's first six years.

Published online: 15 January 2021 https://doi.org/10.1038/s41477-020-00846-1

\footnotetext{
References

1. da Fonseca, R. R. et al. Nat. Plants 1, 14003 (2015).

2. Lozano, R. et al. Nat. Plants https://doi.org/10.1038/s41477-02000834-5 (2021).

3. Bracher, A. et al. Nat. Plants 1, 14002 (2015).

4. Hepworth, C. et al. Nat. Plants https://doi.org/10.1038/s41477020-00828-3 (2021).

5. Jones, H. D. Nat. Plants 1, 14011 (2015).

6. Sanchez, P. A. Nat. Plants 1, 14014 (2015).

7. Eriksson, D. \& Zimny, T. Nat. Plants 6, 1392-1393 (2020).
} 